Çukurova Üniversitesi Mühendislik Mimarlık Fakültesi Dergisi, 33(4), ss. 111-122, Aralık 2018

Çukurova University Journal of the Faculty of Engineering and Architecture, 33(4), pp. 111-122, December 2018

\title{
Güneş Enerjili Bir Sıcak Hava Motoru Tasarımı ve Analizi
}

\author{
Hacer AKHAN*1, Doğan ERYENER ${ }^{1}$ \\ ${ }^{1}$ Trakya Üniversitesi, Mühendislik Mimarlık Fakültesi, Makina Mühendisliği Bölümü, Edirne
}

Geliş tarihi: 15.03.2018 Kabul tarihi: 25.12.2018

$\ddot{O} z$

Giderek artan enerji ihtiyacının daha ucuz ve çevreyi kirletmeyecek yollarla elde edilmesi için alternatif enerji kaynaklarından yararlanılması gerekmektedir. Çevre dostu, yenilenebilir, elde edilmesi düşük maliyetli olan güneş enerjisi, bu durumda en yaygın olarak kullanılan alternatif enerji olarak gündeme gelmiştir. Güneş enerjisi uygulamalarından bir tanesi, güneş enerjisinden elektrik üretimi sağlanması için geliştirilen sıcak hava motoru sistemidir.

Bu çalışma kapsamında ilk olarak özgün bir Stirling sıcak hava motoru tasarlanmış ve bu tasarımın bir prototipi imal edilmiştir. Beta tipi olarak tasarlanan motorda, sıkıştırma oranı, güç pistonu çapı, pistonların bağlı olduğu geri çağrıcı kuvveti oluşturan yaylar, yer değiştirme pistonunun boyu, çalışma akışkanı, doldurma basıncı, ısıtma sıcaklığı, rejeneratör boyutları ve malzemesi değiştirilebilmektedir. Amaç, termodinamik analiz yaparak bu parametrelerin, devir, güç gibi motor karakteristiklerine etkisini incelemektir. Termodinamik analiz sonuçları değerlendirilerek, en yüksek verimi sağlayacak motor parametreleri belirlenmiştir. Motor parametreleri değiştirilebilir bir sistem ilk defa yapılmıştır.

Anahtar Kelimeler: Stirling motoru, Sıcak hava motoru, Güneş enerjili 1sı motoru

\section{Abstract}

Design and Analysis of a Solar Hot Air Engine

Using the energy sources is the subject of discussion to obtain the energy necessity in cheaper and environment friendly. Solar energy, which is nature-friendly, refreshable and of a low cost has become the most widely used alternate energy. One of the systems which works with solar energy are developed to produce electricity from solar energy is hot air engine system.

Within the context of this study, firstly an original Stirling hot air engine was designed, and a prototype of this design was produced. In the engine, which is designed as the beta type, compression level, the diameter of power piston, the arcs which form the back-calling power, to which the pistons are connected, the length of displacer piston, working fluid, filling pressure, heating degree, regenerator size and the material used can be changed. The aim is to analyze the effect of these parameters to engine characteristics like cycle and power and make thermodynamic analyzation. For the first time, a system, of which the engine parameters are adjustable is made.

Keywords: Stirling engine, Hot air engine, Solar powered heat engine

*Sorumlu yazar (Corresponding author): Hacer AKHAN, hacera@trakya.edu.tr 


\section{GíRiș}

Günümüzde, birincil enerji kaynaklarının biteceği düşüncesi, zaman zaman ortaya çıkan enerji krizleri ve dünya nüfusunun sürekli olarak artması ile orta çıkan enerji ihtiyacı, bilim adamlarını alternatif enerji kaynakları bulmaya ve bu kaynakları ihtiyaç olan enerjiye çevirecek makineler üzerinde araştırmalar yapmaya yöneltmektedir. Ayrıca, petrol ve türevi veya fosil yakıtların yakılması sonucu ortaya çıkan zararlı gazlar, çevre ve insan sağlığı üzerinde olumsuz etkiler oluşturmaktadır. $\mathrm{Bu}$ durumda güneş enerjisi, alternatif enerji kaynağı olarak gündeme gelmiştir. Özellikle 1973 yılındaki petrol ambargosu, güneş enerjisi teknolojisinin gelişiminde büyük etken olmuştur. Dünyadaki yaşamın kaynağı olan güneş, temiz enerjilerin ana kaynağıdır. Güneş enerjisi yenilenebilir bir enerji kaynağıdır. İnsanlık için önemli bir sorun kaynağı olan çevreyi kirletici artıkların bulunmayışı, yerel olarak uygulanabilmesi ve karmaşık bir teknoloji gerektirmemesi gibi üstünlükleri sebebiyle son yıllarda üzerinde yoğun çalışmaların yapıldığg bir konu olmuştur.

Binaların 1sıtılması, soğutulması, endüstriyel bitkilerin kurutulması ve elektrik üretimi, güneş enerjisinin yaygın olarak kullanıldığı alanlardır. Güneş enerjisinden elektrik üretimi direkt ve endirekt olarak iki yöntemle gerçekleştirilir. Direkt yöntem kapsamında fotovoltaik sistemler, güneş enerjisinin endirekt biçimde elektriğe dönüştürülmesinde ise güneşten yararlanılarak üretilen buhar ve bunu değerlendiren bir güç çevrimi ya da güneş enerjili sıcak hava motoru ele alınmaktadır. Bunlardan en yaygın olarak kullanılan metot fotovoltaik metottur. Güneş enerjisini doğrudan elektriğe dönüştüren güneş pilleri, yüksek maliyetli ve düşük verimlidir. Son yıllarda güneş enerjisinden elektrik üretimi çalışmalarının başka bir yöne; sıcak hava motorlarına doğru ilerlediği gözlemlenmektedir. Güneş enerjisinden elektrik üretiminde sıcak hava motorlarının kullanılmasında pek çok neden vardır. Her şeyden önce sıcak hava motoru, çok iyi bir termodinamik çevrime sahiptir; iki sıcaklık sınırı arasında teorik olarak en yüksek verim Carnot ve Ericson çevrimleriyle beraber Stirling çevriminden elde edilmektedir. Yapılan çalışmalarda, sıcak hava motorlarından \%30-40 verimle elektrik enerjisi üretildiği belirtilmektedir. Sessiz, çevre dostu bir makine ve düşük sicaklık farklarında bile çalışabilmesi nedeniyle geniş bir uygulama alanı söz konusudur. Sıcak hava motorları denizcilikte ve su altı güç sistemlerinde, elektrik üretiminde, yapay kalp uygulamalarında, otomotivde, soğutma makinelerinde, hidrolik pompalarda, uydu enerji sistemlerinde, uzay roketlerinde ve nükleer güç istasyonlarında kullanılmaktadır.

Sıcak hava motorları, farklı sıcaklıktaki iş akışkanının genişletilmesi ve sıkıştırılması işlemlerinin kapalı ve rejeneratif bir çevrim olan Stirling çevrimi boyunca tekrarlandığ sistemlerdir. Stirling çevrimine göre çalışan bir sicak hava motoru temel olarak iki pistondan oluşmaktadır. Pistonlardan bir tanesi yer değiştirme pistonu olarak adlandırılır ve görevi çevrim akışkanını sıcak ve soğuk bölge arasında nakletmektir. Diğer piston güç pistonu olarak adlandırılır ve motordaki gücü üreten pistondur. Carnot çevriminden bilindiği üzere sıcak ve soğuk 1S1 kaynaklarının sıcaklıkları arasındaki fark arttıkça 1 sıl verim artmaktadır. Dolayısıyla bu sıcaklık farkını arttırmak için Stirling çevriminde sistem içi ısı geçişi yapılır; bu, sistem içi 1sı geçişi, rejeneratör ile sağlanmaktadır. Sıcak hava motorları, teorik olarak en yüksek verime sahip motorlardır. Ayrıca sessiz ve titreşimsiz çalışması, çevre kirliliğine neden olmaması, üretim maliyetinin düşük olması, özel bir yakıta veya enerji kaynağına bağlı kalmadan ısı veren ve ısıya dönüştürülebilen her türlü enerji kaynağı ile çalışabilmesi, montaj ve bakımının kolay ve ucuz yapılması, termik veriminin Carnot çevriminin verimine denk olması ile bu motorlar araştırma konusu olarak gündeme gelmektedir.

İlk olarak Robert Stirling [1] tarafindan 1816'da imal edilmiş ve 4081 orijinal patent numarası ile ilk üretimi gerçekleştirilmiştir. Sıcak hava motorları, 19. yüzyılın son zamanları boyunca değişik tiplerde imal edilerek mekanik güç elde etmek için kullanılmıştır. Güç elde etmek amacıyla buhar makineleri ile uzun süre rekabet etmesi düşünülmüş ve üzerinde uzun süreli araştırmalar yapılmıştır. 1860'lı yıllara kadar Stirling motoru 
teknolojisi geliştirilmeye çalışılmış, ancak 19 . yüzyılın sonlarında yüksek hızlı içten yanmalı motorların geliştirilmesi ve daha yüksek güç elde edilmesiyle, sıcak hava motorların kullanımı azalmış ve yapılan çalışmalar kesintiye uğramıştır. 1930'lu yillardan sonra Philips [2], laboratuvarlarında çalışmaları yeniden başlatıp deneme motorları imal etmiştir. Sıcak hava motorları, yüzyılımızın son yarısında ortaya çıkan enerji krizleri ile tekrar araştırma konusu olmuştur.

Sıcak hava motorlarının ilk icadından bu yana farklı tiplerde birçok motor üretilmektedir. Temelde hepsinin çalışma prensibi aynıdır. Fakat tasarımda karşılaşılan sızdırmazlık, ölü hacim ve benzeri problemlere çözüm bulabilmek için farklı mekanik düzenlemelerde motorlar tasarlanmaktadır. Yücesu [3], alfa tipi bir sıcak hava motoru tasarlamıştır. Temel [4], Stirling çevrimi ile çalışan makinaların rejeneratörlerinin langrange yöntemi ile termodinamik analizini incelemiştir. Koca [5], V tipi Stirling motorunun tasarımını ve imalatını yapmıştır. Yapılan deneysel çalışma sonucunda, 2 bar şarj basıncında $330 \mathrm{~d} / \mathrm{d}$ ile 27,04 W maksimum güç elde edilmiştir. Ünüvar [6], serbest pistonlu Stirling motorunun yer değiştirici yayının dizaynını ve analizini gerçekleştirmiştir. Demiralp [7], gama tipi bir Stirling motorunun tasarımını ve imalatını yapmıştır. İmal edilen gama tipi motordan 920 d/d'da 12,66 W güç elde edilmiştir. Fak1 [8], alfa tipi v modeli bir Stirling motorunun tasarımını ve imalatını yapmıştır. Karataş [9], beta tipi bir Stirling motoru için rhombic döndürme mekanizmasının tasarımını ve imalatını gerçekleştirmiştir. Pırasacı [10], güneş enerjisi ile çalışan, Stirling motorlu elektrik enerjisi üretim sistemi üzerine çalışma yapmıştır. Karabulut ve arkadaşları [11], farklı çalışma gazlarının Stirling motorunun performansina etkilerini deneysel olarak incelenmişlerdir. Demir ve Güngör [12], alfa tipi bir motor imal etmiştir. Motorun, maksimum $1200 \mathrm{~d} / \mathrm{d}$ 'de teorik olarak 20.351 J net iş üretileceği hesaplanmıştır. Hooshang ve arkadaşları [13], sinir ağı kavramlarına dayalı Stirling motorları için yeni bir optimizasyon prosedürü geliştirmiştir. Gheith ve arkadaşları [14], Stirling motoru performansını optimize etmek amacıyla çalışma yapmışlardır. Podesva ve arkadaşları [15], üç farklı mekanizma için piston hareketlerinin analizini ve optimizasyonunu gerçekleştirmişlerdir. Jan ve Marek [16], kendilerinin geliştirdikleri Stirling motorunun matematiksel modellemesini yapmıştır. Erol ve arkadaşları [17], kronolojik olarak Stirling motorlarında yapılan geliştirme çalışmalarını incelemişlerdir. Çınar ve arkadaşları [18], $\alpha$ tipi Stirling motorunun konstrüksiyonu ve performansı üzerine çalışma yapmışlardır. Cheng ve Chen [19], hesaplamalı akışkanlar dinamiği simülasyonuna dayalı $1 \mathrm{~kW}$ 'lık beta tipi Stirling motoru modeli geliştirmişlerdir. Shendage ve arkadaşları [20], 1,5 kW'lik rhombic beta tipi bir Stirling motorunun cevrim analizin ve tasarım parametrelerinin optimizasyonunu yapmışlardır. Alfari ve arkadaşları [21], gama tipi bir Stirling motor simülasyonu ile termodinamik modelleme geliştirmişlerdir. Aksoy ve arkadaşları [22], isi kaynağı olarak $400 \mathrm{~W}$ ve $1000 \mathrm{~W}$ halojen lamba ve çalışma akışkanı olarak Helyum kullanarak, düşük sicaklıklarda çalışan beta tipi bir Stirling motorunun performansını incelemişlerdir. Li ve arkadaşları [23], beta ve gama tipi Stirling motorunun performansını incelemek için politropik bir model geliştirmişlerdir. Tavakolpour-Saleh ve arkadaşları [24], serbest pistonlu bir Stirling motorunun deneysel incelemesini ve matematiksel modellemesini yapmışlardır.

$\mathrm{Bu}$ çalışmanın amacı, güneş enerjisinden ısı ve elektrik enerjisi üretimi yapabilecek bir sicak hava motoru tasarlamak ve bu tasarımın performans değerlendirmesi için bir ön inceleme yapmaktır.

Çalışma esas olarak üç aşamayı kapsamaktadır. Birinci aşamada tasarımın süreci, ikinci aşamada yapılan tasarımın üretim süreci yer almaktadır. Günümüzde sıcak hava motorlarının önündeki en önemli engellerden birisi motor boyutları için gerekli olan hassasiyetlerin sağlanmasıdır. $\mathrm{Bu}$ bakımdan bir sıcak hava motorunun hem tasarım süreci hem de üretim süreci aynı öneme sahiptir. $\mathrm{Bu}$ çerçevede, güneş enerjisinden 1 sı ve elektrik enerjisi üretimi yapabilecek bir sicak hava motorunun tasarımdan üretime geçiş süreci de bu çalışma kapsamında bulunmaktadır. 
Çalışmanın son aşamasında imal edilmiş olan motorun performansı için bir ön inceleme yapılmaktadır. $\mathrm{Bu}$ ön inceleme çerçevesinde motorun termodinamik analizi yapılarak karakteristikleri belirlenmektedir. İmal edilen motorda performansı etkileyen parametreler ayarlanabilir olarak tasarlanmıştır. $\mathrm{Bu}$ çerçevede ayarlanabilir motor boyutlarının sistem performansına etkisinin incelemesi, bu çalışma kapsamında bulunmaktadır.

\section{MOTOR TASARIMI VE IMALATI}

Bu çalışma kapsamında sıcak hava motorlarında karşılaşılan balans, sızdırmazlık, ölü hacim, pistonların geri hareketi, yetersiz isıtma-soğutma yüzeyi, sürtünme kayıpları, genleşme, yer değiștirme pistonunda 1S1 iletimi gibi sorunlara çözüm getirebilecek özgün bir tasarım hedeflenmiştir.

Sızdırmazlık problemi, sıcak hava motorlarında karşılaşılan en önemli problemlerden birisidir. Silindir içindeki iş akışkanının piston çevresinden ve silindirden dışarıya kaçması, motor gücünün ve verimin azalmasına sebep olmaktadır. Sizdırmazlık problemi bu çalışmada iki farklı yöntemle; konstrüksiyon ve malzeme çözümleri ile aşılmaya çalışılmıştır. Sizdırmazlığı en çok etkileyen nedenlerden birisi, motordaki iki pistonun genellikle birbirlerine bir krank-biyel mekanizması ile bağlı olmasıdır. $\mathrm{Bu}$ nedenle prototipte, pistonların geri hareketinin krank-biyel yerine yay mekanizması ile yapılması düşünülmüştür. Böylece pistonların silindir duvarına çarparak aşınmaya neden olması engellenmektedir. Benzer tasarım düşüncesi farklı araştırmacılar ve özellikle NASA'nın Stirling motoru çalışmalarında başarıyla kullanılmıştır. Sızdırmazlık sorununu çözmek için çalışmada aynı zamanda malzeme çözümü uygulanmaktadır. Yapılan tasarımda sizdırmazlığ 1 sağlamak için teflon salmastralar kullanılmıştır. Salmastralar, hareket ve güç pistonları üzerine açılmış kanallara monte edilmektedir.

Motorda, sıcak bölgede sıkıştırma işlemi sonunda elde edilen minimum hacim, rejeneratör hacmi, rejeneratörün her iki yanında yer alan ısıtma ve soğutmanın yapıldığı hacimler ölü hacimdir. Ölü hacimlerin artması motor verimini düşürmektedir. Tasarımda motor bloğunun boyu değişken olduğundan motor farklı minimum hacimlerde çalıștırılarak, en uygun sıkıştırma sonu ölü hacim değeri tespit edilebilmektedir.

Isıtma ve soğutmanın etkin bir şekilde yapılması, Stirling motorunun yüksek verim ile çalışmasını sağlamaktadır. Transfer edilen isı miktarı, transfer kesit alanı ile doğru orantılı olduğundan, temas yüzeyini arttırmak için soğutma elemanı kanatçıklı olarak tasarlanmıştır.

Piston ile silindir arasındaki sürtünme kuvvetinin ihmal edilebilir düzeyde olması için düşey doğrultudaki kuvvet çok küçük olmalıdır. Başka bir deyiş ile piston ağırlığ mümkün olduğu kadar az olmalıdır. Bu amaçla piston malzemesi olarak yoğunluğu düşük olan titanyum, alüminyum ve epoksi seçilmiş ve pistonların içi boşaltılmıştır.

Yer değiştirme pistonu sıcak ve soğuk bölgeler arasında yer almaktadır. İçi boş yapı ile sıcak bölgeden soğuk bölgeye isı geçişinin engellenmesi de amaçlanmıştır. Yer değiştirme pistonu aracılığ ile sıcak bölgeden soğuk bölgeye 1sı transferinin azaltılması motor verimini arttırmaktadır. $\mathrm{Bu}$ nedenle yer değiştirme pistonu içi, 1S1 geçişini azaltacak fiber battaniye ile doldurulmuştur. Seramik battaniyenin isı iletim katsayıs $0,27 \mathrm{~W} / \mathrm{m}^{2 \circ} \mathrm{C}$, yoğunluğu $300 \mathrm{~kg} / \mathrm{m}^{3}$ 'tür. Seramik battaniye arasına yerleştirilen özel alüminyum folyolardan radyasyon kalkanlarının kullanılması ile ışınım ile gerçekleşen isı transferi de önlenmektedir.

Mekanik kayıpları azaltmak için güç pistonunun doğrusal hareketi, krank mili kullanılarak dairesel harekete dönüştürülmemiş, ileri-geri hareket ile çalışan lineer alternatöre bir mil vasıtası ile aktarılması planlanmıştır.

Motor içinde sıcaklığın artması ile motor elemanları genleşmektedir. Birbiri ile temas halinde olan sızdırmazlığı sağlanmış parçaların genleşme katsayıları uyumlu değil ise yükselen sıcaklık etkisi ile parçalar farklı oranlarda 
genleşmektedir. $\mathrm{Bu}$ durumda sistemde gaz kaçakları meydana gelebilmekte veya piston silindir içerisinde sıkışabilmektedir. Bu durumu önlemek için yüksek sıcaklığa maruz kalan hareket pistonu ve silindiri genleşme katsayıları birbirine yakın malzemelerden üretilmiştir.

Tasarımı ve üretimi yapılan sıcak hava motoru prototipinin fotoğrafı Şekil 1'de, şematik resmi Şekil 2'de gösterilmektedir. Motorda birbiriyle eş merkezli olan iki adet piston ve silindir mevcuttur. Pistonlardan birisi gazın sıcak ve soğuk bölge arasında yer değiştirmesini sağlayan yer değiştirme pistonu, diğeri ise mekanik işin elde edildiği güç pistonudur. Genel olarak bir sicak hava motorunun tasarımında, kullanım amacı, gücü, enerji türü, motor devri, çalışma sıcaklıkları ve çalışma akışkanı önceden belirlenmek durumundadır. Bununla birlikte bu araştırmada farklı işletme şartları ve konfigürasyonun etkisi incelenmektedir. Dolayısıyla prototip kullanım amacıyla birlikte farklı işletme şartlarına göre değiştirilebilir bir konstrüksiyona sahip olacak şekilde tasarlanmıştır. Tasarlanan motorda soğuk bölgenin soğutulması için su kullanılacaktır (Çizelge 1).

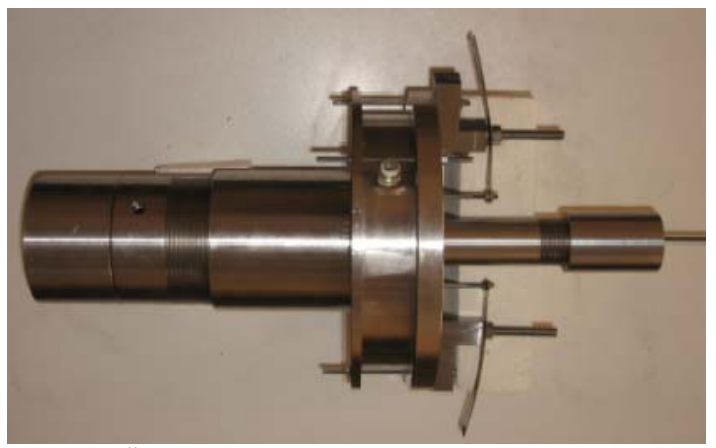

Şekil 1. Üretimi yapılan sıcak hava motoru

Motor için tasarım ve imalata temel olacak, motorun özelliklerine ilişkin bazı kabuller yapılmış, bu kabuller ve motora ait tasarım özellikleri Çizelge 2'de verilmiştir. Bu kabuller yapılırken özellikle literatürde yapılmış olan beta tipi motorların özellikleri ve elde edilen sonuçlar dikkate alınmıştır. Önceki çalışmalarda genel olarak motor boyutlarının belirli değerlerde olduğu görülmektedir. Bir karşılaştırma yapabilmek ve prototipin başarısını ölçebilmek için motor boyutları literatürdekiler ile aynı olacak şekilde alınmıştır.

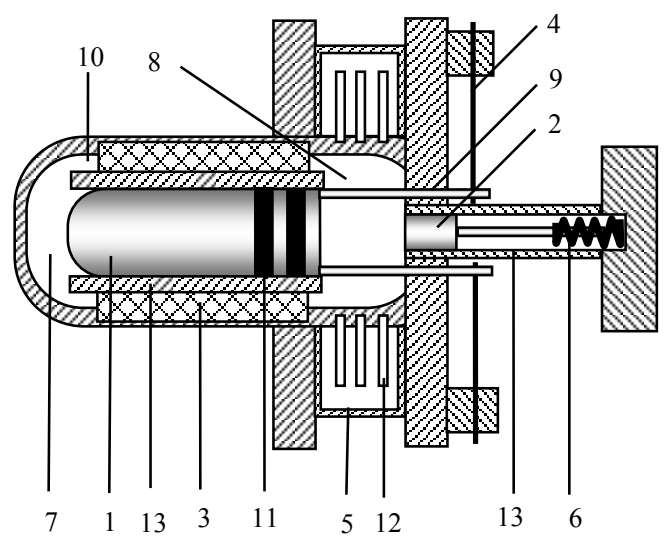

Şekil 2. Sıcak hava motorunun parça ve kısımlarının şematik gösterimi

Çizelge 1. Motor parça ve kısımları

\begin{tabular}{|c|l|}
\hline No & Parça ve Kısım Adı \\
\hline 1 & Yer Değiştirme Pistonu \\
\hline 2 & Güç Pistonu \\
\hline 3 & Rejeneratör \\
\hline 4 & Yaprak Yay \\
\hline 5 & Soğutucu Kısım \\
\hline 6 & Helisel Yay \\
\hline 7 & Sıcak Bölge \\
\hline 8 & Soğuk Bölge \\
\hline 9 & Piston Rotu \\
\hline 10 & Akışkan Aktarma Kanalı \\
\hline 11 & Sızdırmazlık Elemanı \\
\hline 12 & Soğutma Kanatçıkları \\
\hline 13 & Silindir \\
\hline
\end{tabular}

Çizelge 2. Sıcak hava motorunun teknik özellikleri Teknik Özellikler

\begin{tabular}{|c|c|}
\hline Motor Tipi & Beta \\
\hline Yer değiştirme pistonu çapı (mm) & 60 \\
\hline Yer değiștirme pistonu boyu (mm) & En fazla: $183-$ En az: 154 \\
\hline Yer değiştirme pistonu kursu(mm) & En fazla: $55-\quad$ En az: 27 \\
\hline Güç pistonu çapları $(\mathrm{mm})$ & $30-40-50$ \\
\hline Çalışma akışkanı & Hava \\
\hline Yer değiştirme pistonu ağırlı̆̆ $(\mathrm{g})$ & 460 \\
\hline Güç pistonu ağırlıkları (g) & $47,9-62,1-89,9$ \\
\hline Blok boyu $(\mathrm{mm})$ & En fazla: $239-$ En az: 214 \\
\hline Minimum motor hacmi $\left(\mathrm{cm}^{3}\right)$ & 380,7376 \\
\hline Maksimum motor hacmi $\left(\mathrm{cm}^{3}\right)$ & 412,53 \\
\hline Rejeneratör hacmi $\left(\mathrm{cm}^{3}\right)$ & 126,856 \\
\hline Soğuk hacim $\left(\mathrm{cm}^{3}\right)$ & 232,2344 \\
\hline Sicak hacim $\left(\mathrm{cm}^{3}\right)$ & 186,6474 \\
\hline Şarj basıncı (bar) & $0,2-4$ \\
\hline S1cak 1S1 kaynağ1 sıcaklığ $1\left({ }^{\circ} \mathrm{C}\right)$ & 800 \\
\hline Soğuk 1S1 kaynağ 1 sıcaklığ1 $\left({ }^{\circ} \mathrm{C}\right)$ & 400 \\
\hline
\end{tabular}


Çizelge 3'te motor parçaları malzemeleri fiziksel özellikleri yer almaktadır. Malzeme seçimi yapılırken çalışma sıcaklığı, genleşme katsayısı, 1sı iletim katsayısı ve gerekli yerde yoğunluk değerleri dikkate alınmıştır. Üretim yapılırken en uygun özellikteki en ekonomik malzeme seçilmiştir.

Çizelge 3. Motor malzemelerinin fiziksel özelikleri

\begin{tabular}{|c|c|c|c|c|c|}
\hline Motor Elemanı & Malzeme & $\begin{array}{c}\text { Erime } \\
\text { Sıcaklığı } \\
\left({ }^{\circ} \mathrm{C}\right) \\
\end{array}$ & $\begin{array}{l}\text { Genleşme } \\
\text { Katsayısı } \\
\left(10-6 /{ }^{\circ} \mathrm{C}\right) \\
\end{array}$ & $\begin{array}{l}\text { Isı İletim } \\
\text { Katsayısı } \\
\left(\mathbf{W} / \mathbf{m}^{2} \mathbf{K}\right) \\
\end{array}$ & $\begin{array}{l}\text { Yoğunluk } \\
\text { (g/ml) }\end{array}$ \\
\hline \multicolumn{6}{|l|}{ Yer Değiștirme Pistonu } \\
\hline 1. Parça & Titanyum & 1668 & 9,4 & 6,6 & 4,5 \\
\hline 2. Parça & Alüminyum & 660 & 23,8 & 237 & 2,7 \\
\hline 3. Parça & Alüminyum & 660 & 23,8 & 237 & 2,7 \\
\hline 4. Parça & Alüminyum & 660 & 23,8 & 237 & 2,7 \\
\hline \multicolumn{6}{|l|}{ Güç Pistonu } \\
\hline 1. Parça & Epoksi & 450 & 7 & 0,17 & 1,9 \\
\hline 2. Parça & Epoksi & 450 & 7 & 0,17 & 1,9 \\
\hline $\begin{array}{l}\text { Yer Değiştirme Pistonu } \\
\text { Silindiri }\end{array}$ & 310 Paslanmaz & 1600 & 16,2 & 14,2 & 7,75 \\
\hline Güç Pistonu Silindiri & 304 Paslanmaz & 1100 & 16 & 15 & 7,9 \\
\hline \multicolumn{6}{|l|}{ Motor Bloğu } \\
\hline 1. Parça & 310 Paslanmaz & 1600 & 16,2 & 14,2 & 7,75 \\
\hline 2. Parça & 316 Paslanmaz & 1375 & 16,5 & 16,2 & 7,95 \\
\hline 3. Parça & 317 Paslanmaz & 1375 & 16,5 & 16,2 & 7,95 \\
\hline 4. Parça & 318 Paslanmaz & 1375 & 16,5 & 16,2 & 7,95 \\
\hline Soğutma Elemanı & Alüminyum & 660 & 23,8 & 237 & 2,7 \\
\hline Soğutma Ceketi & 304 Paslanmaz & 1100 & 16 & 15 & 7,9 \\
\hline Motor Tablası & 316 Paslanmaz & 1375 & 16,5 & 16,2 & 7,95 \\
\hline Yay Tablası & 304 Paslanmaz & 1100 & 16 & 15 & 7,9 \\
\hline Rodlar & 316 Paslanmaz & 1375 & 16,5 & 16,2 & 7,95 \\
\hline Gaz Doldurma Aparatı & 317 Paslanmaz & 1375 & 16,5 & 16,2 & 7,95 \\
\hline $\begin{array}{l}\text { Basınç Sensörü Bağlama } \\
\text { Aparatı }\end{array}$ & 318 Paslanmaz & 1375 & 16,5 & 16,2 & 7,95 \\
\hline
\end{tabular}

Yer değiştirme pistonun uzunluğu, ayarlanabilmektedir ve görevi çalışma akışkanının sıcak ve soğuk bölgeler arasında hareketini sağlamaktır. Yer değiştirme pistonu, sıcak hava motorlarında karşılaşılan termik ve mekanik sorunları çözebilmek için dört farklı kısımdan yapılmıştır. Güç pistonun çap1 ve kursunun değiştirilebilmesi tasarlanan prototipin bir diğer önemli özelliğidir. Burada piston çapı pratik olarak değiştirilebilmektedir. Böylece piston çapının performansa olan etkisinin incelenmesi hedeflenmektedir. Bütün pistonlar, doğrusal hareket etmektedir.
Stirling çevriminde rejeneratör sabit hacimde 1sıtma ve soğutma işlemlerinde çalışma akışkanının ısı alıp vermesini sağlayan elemandır. Is1, rejeneratör üzerinde depolanarak tekrar kullanılmakta ve isı tasarrufu sağlanmaktadır. Deneysel çalışmalarda, çalışma akışkanı ile rejeneratör arasındaki 1sı transferi, sadece sabit hacim evrelerinde değil, akışkan rejeneratörden geçtiği müddetçe devam etmektedir.

Motor tablası, 316 paslanmaz çelikten imal edilmiştir. Üzerinde soğutma ceketini yerleştirmek için bir kanal yer almaktadır. Güç pistonu silindiri, sıcaklık sensörü ve basınç sensörü bu elemana 
monte edilmektedir. Ayrıca yer değiştirme pistonu rodlarının yataklaması da ara elemanlarla, motor tabasina yapılmaktadır. Motor tablası, saplamalar ile motor bloğu dördüncü parçasına monte edilmiştir. İki eleman arasına soğutma elemanı ve soğutma ceketi yerleştirilmiştir.

Prototipin en önemli elemanlarından birisi de pistonların dönüş hareketlerini sağlayacak yaylardır. Dönüş hareketinin istenen hızda ve kursta olması için yay katsayısı ve yay uzunluğu çok önemlidir. Farklı işletme şartları için yaydan istenen özellikler değişeceğinden; prototip buna uygun olarak ayarlanabilir tasarlanmıştır. Prototip üzerindeki yay bağlantıları hareketli elemanlarla olacak şekilde tasarlanmış ve böylece farklı yayların ve yay katsayılarının kullanımına imkan tanınmıştır. Böylece motorun en uygun yay mekanizması ile çalıştırılması hedeflenmektedir.

Soğutma sistemi, soğutma elemanı ve soğutma ceketinden oluşmaktadır. Soğutma akışkanı olarak su kullanılmaktadır.

Stirling motorlarında çalışma akışkanı olarak hava, helyum ve hidrojen gibi gazlar kullanılmaktadır. Helyum ve Hidrojenin izentropik üssü yüksek olduğu için, çalışma akışkanı olarak kullanıldıklarında motor verimi artmaktadır. Fakat Hidrojenin yanıc bir gaz, Helyumunda pahalı olması nedeni ile sıcak hava motorlarında daha çok hava kullanılmaktadır. Havanın ekonomik olarak maliyeti yoktur.

İmalatı yapılan motor için çalışma akışkanı olarak hava seçilmiştir. Motora bağlı bir gaz doldurma aparatı ile gerekli görüldüğü zaman motor içine hava basılmakta veya tahliye edilmektedir.

Parçalanın yüzey kaliteleri ve pürüzlülük değerleri imalat yöntemine bağlıdır. Parçaların çalışma durumları ve üretim metotları dikkate alınarak yüzey kaliteleri belirlenmiştir. Hassas yüzey kaliteleri, hassas tezgahlarda uygun kesici takımla işlenmiş parçalarda elde edilmektedir. Maliyeti arttırmamak için yüzeyler gerektiği kadar düzgün ve pürüzsüz olmalıdır. İmalat sürecinde torna, freze, taşlama, planya tezgahları ve matkap ile talaş kaldırma işlemleri gerçekleştirilmiştir. İmalatı yapılan motor parçalarına, yüzey sertleştirme işlemleri uygulanmamıştır [25].

\section{TERMODINAMIK ANALIZZ}

Stirling çevrimi sıcak hava motorları için ideal bir çevrimdir. Dört tümden tersinir hal değişiminden oluşan Stirling çevriminin P-V diyagramı Şekil 3'te görülmektedir. Bu hal değişimleri aşağıda sıralanmıştır:

1-2 İzotermal (Sabit sıcaklık) sıkıştırma (Sistemden diş ortama ısı geçişi)

2-3 Sabit hacimde rejenerasyon (Rejeneratörden aracı akışkana sistem içi ısı transferi)

3-4 İzotermal (Sabit sıcaklık) genişleme (Sisteme dış kaynaktan ısı geçişi)

4-1 Sabit hacimde rejenerasyon (Aracı akışkandan rejeneratöre sistem içi 1sı geçişi)

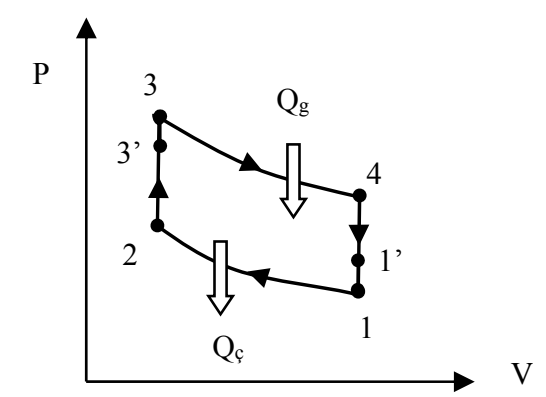

Şekil 3. Stirling çevrimi P-V değişimi

1-2 sabit sıcaklıkta sıkıştırma işlemi hal denklemi Eşitlik 1 ile ifade edilmektedir.

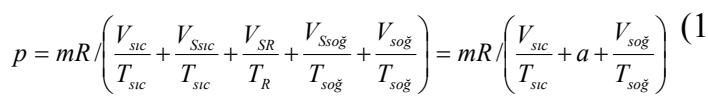

Eşitlik1'de yer alan $\alpha$ hesaplama parametresi Eşitlik 2 ile ifade edilmektedir.

$a=\frac{V_{S s c c}}{T_{s i c}}+\frac{V_{S R}}{T_{R}}+\frac{V_{S s o \check{g}}}{T_{\text {soğ }}}$

Sıkıştırma işleminde, soğuk bölgedeki çalışma akışkanı, $V_{\text {soğ } 1}=V_{D}+V_{P}$ hacminden $V_{\text {soğ } 2}=V_{D}$ hacmine sıkıştırılmaktadır. Bu işlem boyunca sıcak bölgedeki çalışma akışkanının süpürme hacmi 
sıfirdır. 1-2 izotermal sıkıştırma işlemi süresince atılan 1s1, Eşitlik 3-5 ile hesaplanmaktadır.

$$
\begin{aligned}
& Q_{1-2}=W_{1-2}=\int_{V_{C 1}}^{V_{C 2}} p d V_{s o \check{g}}=m R T_{s o \check{g}} \int_{V_{C 1}}^{V_{C 2}} \frac{d V_{\text {soğ }}}{\left(V_{s o g ̆ g}+a T_{s o \check{g}}\right)} \\
& Q_{1-2}=m R T_{\text {soğ }} \ln \left[\left(V_{\text {soğ } 2}+a T_{\text {soğ }}\right) /\left(V_{\text {soğ } 1}+a T_{\text {soğ }}\right)\right] \\
& Q_{1-2}=m R T_{\text {soğ }} \ln \left\lfloor\left(V_{D}+a T_{\text {soğ }}\right) /\left(V_{D}+V_{P}+a T_{\text {soğ }}\right)\right]
\end{aligned}
$$

Çevrimde rejeneratör için mükemmel kabulü yapılmazsa, bu hal değişimi boyunca rejeneratöre verilen 1s1, Eşitlik 6 ile ifade edilmektedir.

$Q_{2-3^{\prime}}=m C_{V}\left(T_{3^{\prime}}-T_{2}\right)=e m C_{V}\left(T_{s c c}-T_{s o g ̆ g}\right)$

3'-3 işlemi boyunca dış kaynaklardan transfer edilen 1sı miktarı, Eşitlik 7 ile hesaplanmaktadır.

$Q_{3-3^{\prime}}=m C_{V}\left(T_{s c c}-T_{3^{\prime}}\right)=(1-e) m C_{V}\left(T_{s c c}-T_{s o g ̆}\right)$

Genişleme işleminde, sıcak bölgedeki iş akışkanının hacmi $V_{s l l} 3=V_{D}$ hacminden $V_{s l 4}=V_{D}+V_{P}$ hacmine kadar genişlemektedir. $\mathrm{Bu}$ hal değişimi boyunca soğuk bölgedeki akışkanın süpürme hacmi sıfırdır. 3-4 sabit sıcaklıkta genişleme işlemi boyunca çevrime verilen 1s1, Eşitlik 8-10 ile hesaplanmaktadır.

$Q_{3-4}=W_{3-4}=m \int_{V_{s c c}}^{V_{s c 4}} p d V_{s c c}=m R T_{s c c}^{V_{s c c}} \int_{V_{s c c}}^{V_{s c}} \frac{d V_{s c c}}{\left(V_{s c}+a T_{s c c}\right)}$

$Q_{3-4}=m R T_{s c c} \ln \left[\left(V_{s c 4}+A T_{s c c}\right) /\left(V_{s c 3}+a T_{s c c}\right)\right]$

$Q_{3-4}=m R T_{s c c} \ln \left[\left(V_{D}+V_{P}+A T_{s c c}\right) /\left(V_{D}+a T_{s c c}\right)\right]$

Mükemmel olmayan rejeneratör tarafindan depolanan 1sı miktarı, Eşitlik 11 ile ifade edilmektedir.

$Q_{4-1}=m C_{V}\left(T_{1^{\prime}}-T_{4}\right)=-e m C_{V}\left(T_{s c c}-T_{s o g ̆ g}\right)$

1'-1 hal değişimi süresinde çevrimden dışarıya atılan ısı miktarı, Eşitlik 12 ile hesaplanmaktadır.
$Q_{1-1^{\prime}}=m C_{V}\left(T_{s o g ̆ g}-T_{1^{\prime}}\right)=-(1-e) m C_{V}\left(T_{s c c}-T_{s o g ̆ g}\right)$

Soğutma işleminde transfer edilen 1S1 miktarı rejeneratörün etkinliğine bağlıdır. Rejeneratörün ideal olmadığı düşünülürse, çevrime giren toplam 1Sı miktarı, Eşitlik 13-15 ile ifade edilmektedir.

$Q_{g}=Q_{3-3^{\prime}}+Q_{3-4}$

$Q_{g}=m C_{V}\left\{\left(T_{s c c}-T_{3^{\prime}}\right)+(x-1) T_{s c c} \ln \left[\frac{\left(V_{s c c}+A T_{s c c}\right)}{\left(V_{s c c}+\alpha T_{s c c}\right)}\right]\right\}$

$\mathrm{Q}_{\mathrm{g}}=\mathrm{mC}_{\mathrm{v}}\left\{(1-\mathrm{e})\left(\mathrm{T}_{\text {sic }}-\mathrm{T}_{\text {soğ }}\right)+(\mathrm{x}-1) \mathrm{T}_{\text {scc }} \ln \left[\frac{\left(\mathrm{V}_{\mathrm{D}}+\mathrm{V}_{\mathrm{p}}+\mathrm{AT}_{\text {scc }}\right)}{\left(\mathrm{V}_{\mathrm{D}}+\alpha \mathrm{T}_{\text {scc }}\right)}\right]\right\}$

$\chi$ özgül 1sı oranıdır. Çevrime giren 1s1 miktarı, rejeneratör etkinliğine ve ölü hacimlere bağlıdır. Rejeneratörün mükemmel olmadığı düşünülürse çevrimden atılan toplam isı Eşitlik 16-18 ile hesaplanmaktadır.

$Q_{\zeta}=Q_{1-1^{\prime}}+Q_{1-2}$

$Q_{\zeta}=-m C_{V}\left\{\left(T_{\text {sŏ̆ }}-T_{1^{\prime}}\right)+(x-1) T_{\text {soğ }} \ln \left[\frac{\left(V_{\text {sŏg } 1}+a T_{\text {soğ }}\right)}{\left(V_{\text {sog } 2}+\alpha T_{\text {sog }}\right)}\right]\right\}$

$Q_{\zeta}=-m C_{V}\left\{(1-e)\left(T_{s c t}-T_{s o \check{g}}\right)+(x-1) T_{\text {soğ }} \ln \left[\frac{\left(V_{D}+V_{P}+a T_{\text {sŏ }}\right)}{\left(V_{D}+\alpha T_{\text {sog }}\right)}\right]\right\}$

Rejeneratör için mükemmel kabulü yapılmadan, çevrim net işi, Eşitlik 19-21 ile ifade edilmektedir.

$W_{n e t}=\sum Q=Q_{g}-Q_{\zeta}=Q_{3-3^{\prime}}+Q_{3-4}+Q_{1-1^{\prime}}+Q_{1-2}$

$W_{n e t}=Q_{3-4}+Q_{1-2}$

$W_{n e t}=m R\left\{T_{s c c} \ln \left[\frac{\left(V_{s c 4}+a T_{s c c}\right)}{\left(V_{s c c 3}+\alpha T_{s c c}\right)}\right]-T_{s o \check{g}} \ln \left[\frac{\left(V_{\text {soğ } 1}+a T_{s o g ̆ g}\right)}{\left.V_{s o g}+T_{s o g}\right)}\right]\right\}$

$V_{s c c}=V_{s o g ̆ 1}=V_{D}+V_{P}=V_{1}$ ve $V_{s l c 3}=V_{s o \check{2} 2}=V_{D}=V_{2}$ eșitlikleri kullanılarak denklem yeniden düzenlenirse Eşitlik 22 net iş denklemi elde edilmektedir. 


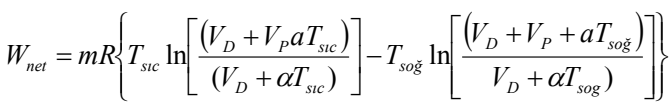

$\mathrm{Ne}$ iş, çevrim ortalama efektif basıncından da hesaplanmaktadır. Toplam hacim değişimi $V_{s c c 4}-V_{3}=V_{\text {soğ } 1}-V_{\text {soğ } 2}=V_{1}-V_{2}=V_{P} \quad$ şeklinde yazılmaktadır.

$W_{n e t}=p_{m} V_{P}$

Eşitlik 22 ve 23 kullanılarak ortalama efektif basınç denklemi Eşitlik 24 yazılmaktadır.

$\mathrm{p}_{\mathrm{m}}=\left(\frac{\mathrm{mR}}{\mathrm{V}_{\mathrm{P}}}\right)\left\{\mathrm{T}_{\mathrm{scc}} \ln \left[\frac{\left(\mathrm{V}_{\mathrm{D}}+\mathrm{V}_{\mathrm{P}}+\alpha \mathrm{T}_{\text {sc }}\right)}{\left(\mathrm{V}_{\mathrm{D}}+\alpha \mathrm{T}_{\text {scc }}\right)}\right]-\mathrm{T}_{\text {soğ }} \ln \left[\frac{\left(\mathrm{V}_{\mathrm{D}}+\mathrm{V}_{\mathrm{p}}+\alpha \mathrm{T}_{\text {sog }}\right)}{\left(\mathrm{V}_{\mathrm{D}}+\alpha \mathrm{T}_{\text {sog }}\right)}\right]\right\}$

Eşitlik 24'den ortalama efektif basıncın ölü hacimlere bağımlı olduğu görülmektedir. Ölü hacimleri ihmal ederek, mükemmel gaz yasasını ve $T_{\text {soğ }}=T_{2}$ ve $V_{2}=V_{3} \quad$ eşitliklerini kullanarak Eşitlik 24 düzenlenerek, Eşitlik 25 ve 26 elde edilmektedir.

$$
\begin{aligned}
& p_{m}=\left[\left(p_{3}-p_{2}\right) V_{3} /\left(V_{1}-V_{2}\right)\right] \ln \left(V_{1} / V_{2}\right) \\
& P_{m}=\left[\left(P_{3}-P_{2}\right) /\left(V_{1} / V_{2-1}-1\right)\right] \ln \left(V_{1} / V_{2}\right)
\end{aligned}
$$

Sıcak hava motorunun termal verimi Eşitlik 26 ile ifade edilmektedir.

$\eta=\frac{W_{n e t}}{Q_{g}}$

\section{MOTOR PERFORMANSI}

Yapılan termodinamik analizde çalışma akışkanının maksimum sıcaklığı $800^{\circ} \mathrm{C}$, minimum sıcaklığ $1400{ }^{\circ} \mathrm{C}$ olarak alınmıştır. Yüksek sıcaklık uygulamas1 $\quad\left(400 \quad{ }^{\circ} \mathrm{C}-1200{ }^{\circ} \mathrm{C}\right.$ arası [26]) kategorisine giren motor, maksimum $1200{ }^{\circ} \mathrm{C}$ sıcaklıkta çalışabilecek şekilde tasarlanmıştır. Fakat 1sıl gerilmeleri azaltmak için maksimum çalışma sıcaklığı $800 \quad{ }^{\circ} \mathrm{C}$ seçilmiştir. Yüksek sıcaklık kategorisi kapsamında çalışabilmek için minimum sıcaklık $400{ }^{\circ} \mathrm{C}$ değerindedir. İmalatı yapılan motorun güç pistonu kursu, yer değiştirme pistonu kursu, güç pistonu çap1, şarj basıncı değerleri değişken olarak seçilmiştir. Termodinamik analizde, 0,2-0,25-0,3 bar olmak üzere üç farklı şarj basıncı kullanılmıştır. Yer değiştirme pistonu kursu, maksimum 0,05 m, minimum $0,01 \mathrm{~m}$ olarak, güç pistonu kursu maksimum 0,03 $\mathrm{m}$, minimum $0,01 \mathrm{~m}$ olarak hesaplamalara alınmıştır. Güç pistonu çapı ise 0,03-0,04-0,05 m olmak üzere farklı üç değere sahiptir. Yer değiştirme pistonunun çap1 $0,06 \mathrm{~m}$ sabit değerdedir. Yapılan hesaplamalarda rejeneratör sıcaklığ $577^{\circ} \mathrm{C}$ olarak belirlenmiştir.

Termodinamik analiz verilerine göre, şarj basıncı 0,3 bar, yer değiştirme pistonu kursu $0,03 \mathrm{~m}$, güç pistonu kursu $0,03 \mathrm{~m}$ ve güç pistonu çap1 $0,05 \mathrm{~m}$ olarak seçildiğinde \%63 maksimum termal verim değeri elde edilmiştir. Motor veriminin arttırılması için tek başına şarj basıncının artırılması yeterli değildir. Maksimum termal verime ulaşıldığında ortalama efektif basınç 2,1 bar, net iş 12,5 J olarak hesaplanmıştır. Ayrıca yapılan analizde elde edilen en yüksek net iş değeri 12,5 J'dür. Analiz sonuçlarına göre güç pistonu çapı ve kursu, yer değiştirme pistonu kursu ve şarj basıncı değerleri değişimi ile net iş değerindeki değişim doğru orantilidir.

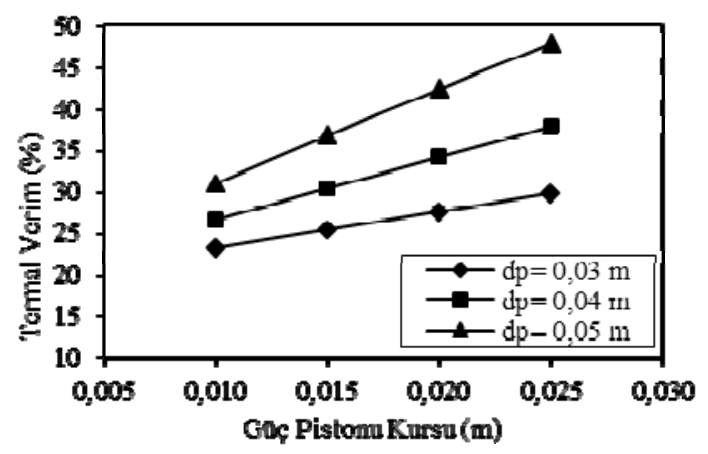

Şekil 4. $P=0,25$ bar, $x_{d}=0,025 \mathrm{~m}$ ve farklı güç pistonu çapları değerleri için termal verim ile güç pistonu kursu arasındaki değişim

Şekil 4'de görüldüğü gibi güç pistonu çap1 ve kursu arttıkça termal verim de artmaktadır. Şekil 5'de $\mathrm{P}=0,25$ bar, $\mathrm{x}=0,02 \mathrm{~m}$ ve farklı güç pistonu çapları değerleri için termal verim ile yer 
değiştirme pistonu kursu arasındaki değişim görülmektedir. Yer değiştirme pistonu kursunun artması da termal verimi artırmaktadır.

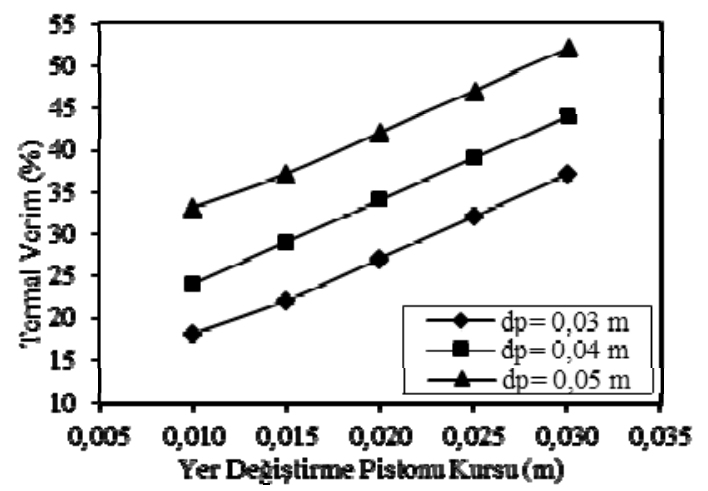

Şekil 5. $\mathrm{P}=0,25$ bar, $\mathrm{x}=0,02 \mathrm{~m}$ ve farklı güç pistonu çapları değerleri için termal verim ile yer değiştirme pistonu kursu arasındaki değişim

Yapılan analiz sonuçlarına göre, güç pistonu çapı ve kursu arttıkça, ortalama efektif basınç azalmakta, şarj basıncı ve yer değiştirme pistonu kursu arttıkça ortalama efektif basınç artmaktadır. Termodinamik analiz verilerine göre, maksimum ortalama efektif basınç 12,8 bar'dır. Bu maksimum değeri elde edebilmek için şarj basıncı 0,3 bar, güç pistonu kursu $0,03 \mathrm{~m}$, yer değiştirme pistonu kursu $0,05 \mathrm{~m}$ ve güç pistonu çapı $0,03 \mathrm{~m}$ olarak seçilmelidir. 12,8 bar ortalama efektif basınca ulaşııldığında termal verim $\% 54,2$, net iş $9 \mathrm{~J}$ olarak hesaplanmıştır.

Şekil 6'da $\mathrm{x}_{\mathrm{p}}=0,015 \mathrm{~m}, \mathrm{x}_{\mathrm{d}}=0,02 \mathrm{~m}$ ve farklı şarj basınçları değerleri için net iş ile güç pistonu çapı arasındaki değişim görülmektedir. Güç pistonu çapı ve kursu, şarj basıncı, yer değiştirme pistonu kursu ile motor net iși doğru orantıll olarak değişmektedir. Şekil 7'de $x_{d}=0,25 \mathrm{~m}, \mathrm{~d}_{\mathrm{p}}=0,03 \mathrm{~m}$ ve farklı güç pistonu kursu değerleri için termal verim ile şarj basıncı arasındaki değişim yer almaktadır. Diğer değişkenleri sabit tutarak şarj basıncının değiştirilmesi termal verimi etkilememektedir. Şekil 8'de $\mathrm{P}=0,25$ bar, $\mathrm{X}_{\mathrm{d}}=0,025 \mathrm{~m}$ ve farklı güç pistonu kursu değerleri için termal verim ile güç pistonu çapı arasındaki değişim, Şekil 9'da $\mathrm{P}=0,25$ bar, $\mathrm{d}_{\mathrm{p}}=0,03 \mathrm{~m}$ ve farklı yer değiştirme pistonu kursu değerleri için termal verim ile güç pistonu kursu arasındaki değişim görülmektedir. Yer değiştirme pistonunun kursu, güç pistonu kursu ve çapı ile termal verim doğru orantılı olarak değişmektedir.

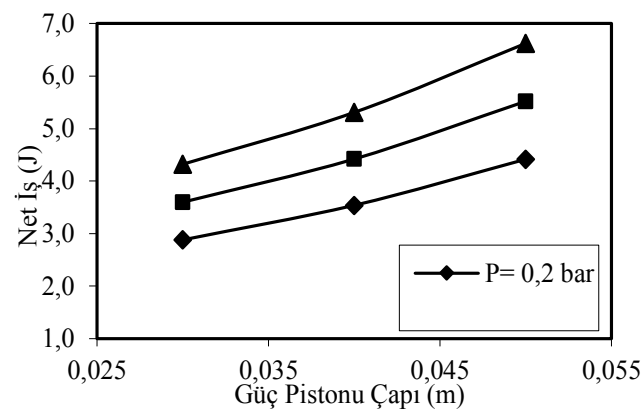

Şekil 6. $x_{p}=0,015 \mathrm{~m}, \mathrm{x}_{\mathrm{d}}=0,02 \mathrm{~m}$ ve farkl1 şarj basınçları değerleri için net iş ile güç pistonu çapı arasındaki değişim

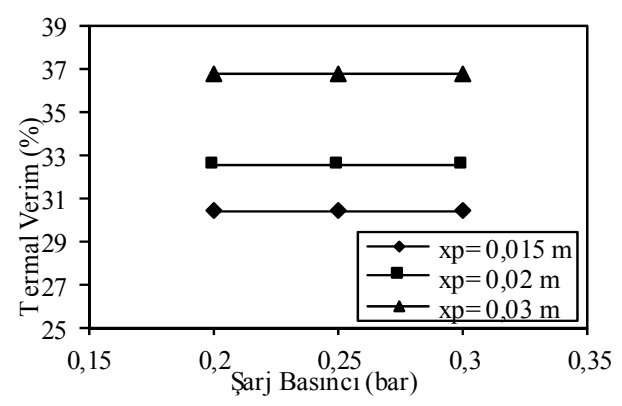

Şekil 7. $\mathrm{x}_{\mathrm{d}}=0,25 \mathrm{~m}, \mathrm{~d}_{\mathrm{p}}=0,03 \mathrm{~m}$ ve farklı güç pistonu kursu değerleri için termal verim ile şarj basıncı arasındaki değișim

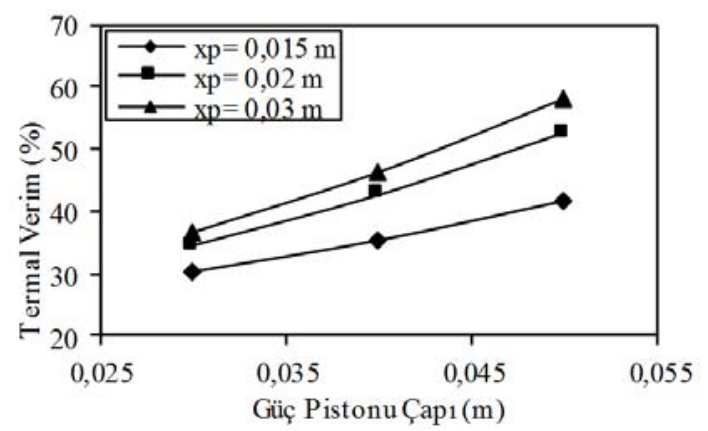

Şekil 8. $P=0,25$ bar, $x_{d}=0,025 \mathrm{~m}$ ve farklı güç pistonu kursu değerleri için termal verim ile güç pistonu çapı arasındaki değişim 


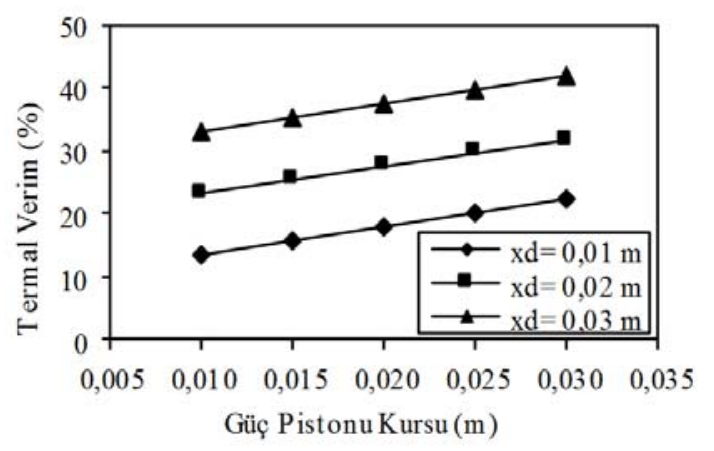

Şekil 9. $P=0,25$ bar, $d_{p}=0,03 \mathrm{~m}$ ve farklı yer değiştirme pistonu kursu değerleri için termal verim ile güç pistonu kursu arasındaki değişim

\section{SONUÇ}

Ülkemizdeki yenilenebilir enerji kaynaklarının en önemlisi güneştir. Günümüzde kurutma, su ve mekan 1sıtma gibi alanlarda güneş enerjisi yaygın olarak kullanılsa da enerji üretim amaçlı güneş enerjisi teknolojilerinin kullanılması sağlanamamıştır. Ülkemizdeki enerji ihtiyacı göz önüne alındığında güneş enerjisi teknolojisi geliştirilerek, bu enerjiyi ihtiyaç olan diğer enerjilere çevirecek makineler üzerine yapılan çalışmaları yaygınlaştırmak gerekmektedir.

Geniş kapsamlı uygulama alanlarına sahip olan, sıcak hava motorları birçok alternatif enerji kaynağ 1 kullanılarak çalıştırılabildiğinden ve çevreci bir motor olduğundan geleceğin motorları olarak görülmektedir. Günümüzde yapılan birçok araştırma ve dizayn çalışmalarının doğrultusu, sıcak hava motorlarının her türlü alana adaptasyonunu sağlayacak yöndedir.

Motorda sızdırmazlık problemi çözülerek, optimum çalışma sıcaklığı ve basıncı belirlenebilir. $\mathrm{Bu}$ çalışma ortamını sağladıktan sonra motorda çalışma akışkanı olarak hava yerine helyum, azot veya hidrojen kullanıldığında daha yüksek verim elde edilecektir. Ayrıca motorda ölü hacimler mümkün olduğu kadar azaltılmalı, sıkıştırma oranı mümkün olduğu kadar arttırılmalıdır.

\section{TEŞEKKÜR}

$\mathrm{Bu}$ araştırma Trakya Üniversitesi Bilimsel Araştırma Projesi Fonu tarafindan desteklenmiştir (Proje Numarasi: TÜBAP-2006/753).

\section{KAYNAKLAR}

1. Organ, A.J., 1992. Thermodynamics and Gas Dynamics of Stirling Cycle Machine', Cambridge, UK.

2. Martini, W.R., 1983. Stirling Engine Design Manual, U.S. Department of Energy Conservation and Renewable Energy Office of Vehicle and Engine R\&D

3. Yücesu, S., 1996. Küçük Güçlü Güneş Enerjili Bir Stirling Motoru Tasarımı, Doktora Tezi, Gazi Üniversitesi.

4. Temel, M., 1996. Stirling Çevrimi ile Çalışan Makinaların Rejeneratörlerinin Langrange Yöntemi ile Termodinamik Analizi, Yüksek Lisans Tezi, Gazi Üniversitesi

5. Koca, A., 1997. V Tipi Stirling Motorunun Tasarımı ve İmali, Doktora Tezi, Gazi Üniversitesi.

6. Ünüvar, E., 1998. Serbest Pistonlu Stirling Motorunun Yer Değiştirici Yayının Dizaynı ve Analizi, Yüksek Lisans Tezi.

7. Demiralp, M., 2000. Gama Tipi Bir Stirling Motorun Tasarımı ve İmalatı, Doktora Tezi, Gazi Üniversitesi.

8. Fakı, A., 2001. Alfa Tipi V Modeli Bir Stirling Motorunun Tasarımı ve İmalatı, Yüksek Lisans Tezi, Dumlupınar Üniversitesi.

9. Karataş, O., 2002. Beta Tipi Bir Stirling Motoru için Rhombic Döndürme Mekanizmasının Tasarımı ve İmali, Yüksek Lisans Tezi, Gazi Üniversitesi.

10. Pırasacı, T., 2002. Güneş Enerjisi ile Çalışan, Stirling Motorlu Elektrik Enerjisi Üretim Sistemi, Yüksek Lisans Tezi, Gazi Üniversitesi.

11. Karabulut, H., Yücesu, H.S., Çınar, C., 2006. Nodal Analysis of a Stirling Engine with Concentric Piston and Displacer, Renewable Energy, 31(13), 2188-2221.

12. Demir, B., Güngör, A., 2010. Manufacturing and Testing of a V-Type Stirling Engine, 
International Journal of Electronics, Mechanical and Mechatronics Engineering, 1, (1), 39-44.

13. Hooshang, M., Askari Moghadam, R., Alizadeh Nia, S., Tale Masouleh, M., 2015. Optimization of Stirling Engine Design Parameters Using Neural Networks, Renewable Energy, 74, 855-866.

14. Gheith, R., Hachem, H., Aloui, F., Ben Nasrallah S., 2015. Experimental and Theoretical Investigation of Stirling Engine Heater: Parametrical Optimization, Energy Conversion and Management, 105, 285-293.

15. Podesva, J., Poruba, Z., 2016. The Stirling Engine Mechanism Optimization, Perspectives in Science, 7, 341-346.

16. Jan, W., Marek, P., 2016. Mathematical Modeling of the Stirling Engine, Procedia Engineering, 157, 349-356.

17. Erol, D., Yaman, H., Doğan, B., 2017. A Review Development of Rhombic Drive Mechanism Used in the Stirling Engines, Renewable and Sustainable Energy Reviews, 78, 1044-1067.

18. Çınar, C., Aksoy, F., Solmaz, H., Yılmaz, E., Uyumaz, A., 2018. Manufacturing and Testing of an a-type Stirling Engine, Applied Thermal Engineering, 130, 1373-1379.

19. Cheng, C.H., Chen, Y.F., 2017. Numerical Simulation of Thermal and Flow Fields Inside a 1-kW Beta-type Stirling Engine, Applied Thermal Engineering, 121, 554-561.

20. Shendage, D.J., Kedare, S.B., Bapat, S.L., 2017. Cyclic Analysis and Optimization of Design Parameters for Beta Configuration Stirling Engine Using Rhombic Drive, Applied Thermal Engineering, 124, 595-615.

21. Alfarawi, S., AL-Dadah, R., Mahmoud, S., 2016. Enhanced Thermodynamic Modelling of a Gamma-type Stirling Engine, Applied Thermal Engineering, 106, 1380-1390.

22. Aksoy, F., Karabulut, H., Çınar, C., Solmaz, H., Ozgoren, Y.O., Uyumaz, A., 2015. Thermal Performance of a Stirling Engine Powered by a Solar Simulator, Applied Thermal Engineering, 86, 161-167.

23. Li, R., Grosu, L., Li, W., 2017. New Polytropic Model to Predict the Performance of Beta and
Gamma Type Stirling Engine, Energy, 128, 62-76.

24. Tavakolpour-Saleh, A.R., Zare, SH., Bahreman, H., 2017. A Novel Active Free Piston Stirling Engine: Modeling, development, and experiment, Applied Energy, 199, 400-415.

25. Akhan, H., (Tez Yöneticisi: Doğan Eryener), 2007. Güneş Enerjili Bir Sicak Hava Motoru Tasarımı, Yüksek Lisans Tezi, Trakya Üniversitesi Fen Bilimleri Enstitüsü.

26. Isısan, 2008. 376 Nolu Isısan Çalışmaları, Yenilenebilir Enerji Alternatif Sistemler.

\section{SEMBOLLER}

$\alpha$ : Denklem (1) hesaplama parametresi

$\mathrm{C}_{\mathrm{p}}$ : Sabit basınçta özgül ısı (kJ/kg.K)

e: Rejeneratör etkinlik katsayısı

m: Çalışma akışkanı kütlesi, (kg)

P: Şarj basınc1, (bar)

$P_{\text {ort }}$ :Ortalama etkin basınç (bar)

$\mathrm{P}_{\mathrm{m}}$ : Ortalama efektif basınç

Q: Isı (J)

R: Gaz sabiti, (kJ/kg.K)

T: Sicaklık, $\left({ }^{\circ} \mathrm{C}\right.$ veya $\left.\mathrm{K}\right)$

$\mathrm{V}$ : Hacim, $\left(\mathrm{m}^{3}\right)$

$\mathrm{W}$ : Motor gücü (Watt)

$\mathrm{W}_{\text {net }}$ : Motor net işi

$\chi$ : Özgül 1sı kapasitesi oranı

$\eta$ : Verim

\section{İndisler}

1: 1 durumundaki değer

1 ': Rejeneratör girişi değeri

2: 2 durumundaki değer

3: 3 durumundaki değer

3': Rejeneratör çıkışı değeri

4: 4 durumundaki değer

ç: Çıkan

D: Yer değiştirme pistonu

g: Giren

net: Net

P: Güç pistonu

S: Ölü hacim

sic: Sicak

soğ: Soğuk 